\title{
Desenvolvimento, produção e qualidade dos frutos de pessegueiros enxertados sobre diferentes porta-enxertos
}

\section{Development, production and quality of fruits of peach trees grafted on different rootstocks}

\author{
Andressa Comiotto ${ }^{1 *}$; José Carlos Fachinello \\ Alexandre Hoffmann ${ }^{3}$; Simone Padilha Galarça ${ }^{4}$; \\ Nicácia Portella Machado ${ }^{4}$; Marcos Ernani Prezotto5; Luciane Both Hass ${ }^{5}$
}

\section{Resumo}

O trabalho objetivou avaliar o vigor, a época de floração, a produção e a qualidade de pêssegos das cultivares Maciel e Chimarrita sobre os porta-enxertos Aldrighi, Capdeboscq, Flordaguard, Nemaguard, Okinawa e Umezeiro. O experimento foi conduzido a campo na Embrapa Uva e Vinho, em Bento Gonçalves/RS. As variáveis vegetativas e produtivas foram analisadas a campo e as análises físicoquímicas dos frutos foram realizadas na Faculdade de Agronomia Eliseu Maciel (Universidade Federal de Pelotas - Pelotas/RS), nas safras de 2008 e 2009. De acordo com os resultados obtidos, concluiu-se que 'Maciel' e 'Chimarrita', quando enxertadas sobre 'Umezeiro', apresentam menor vigor e sintomas de incompatibilidade. A floração dos pessegueiros 'Maciel'e 'Chimarrita' é influenciada pelos portaenxertos, podendo o início e a plena floração retardar ou antecipar em até onze dias. A produção e a produtividade acumuladas estimadas por hectare de 'Maciel' são maiores quando enxertadas sobre 'Flordaguard' e menores sobre 'Umezeiro'.

Palavras-chave: Prunus persica (L.) Batsch, comportamento vegeto-produtivo, sólidos solúveis, incompatibilidade, pêssego

\footnotetext{
Abstract

The objective of this work was to evaluate the vigour, flowering time, production and fruit quality of peaches from the cultivars 'Maciel' and 'Chimarrita' grafted on rootstocks 'Aldrighi', 'Capdeboscq', 'Flordaguard', 'Nemaguard', 'Okinawa' and 'Umezeiro'. The experiment was conducted at the Embrapa Uva e Vinho, in Bento Gonçalves/RS. Vegetative and productive variables were analyzed in the field, and the physical-chemical analysis of the fruits were held at the Faculdade de Agronomia Eliseu Maciel (Universidade Federal de Pelotas - UFPel, Pelotas, Rio Grande do Sul, Brazil), during the 2008 and 2009 seasons. According to the results, it was concluded that the Maciel and Chimarrita cultivars grafted on 'Umezeiro' are less vigorous, and showed symptoms of incompatibility. The flowering of the peach trees from cultivars Maciel and Chimarrita is influenced by the rootstocks, which may delay

${ }^{1}$ Prof $^{\mathrm{a}} \mathrm{Dr}^{\mathrm{a}}$ do Instituto Federal de Educação Ciência e Tecnologia do Rio Grande do Sul, 1FRS, câmpus Bento Gonçalves, Bento Gonçalves, RS. E-mail: andressacomiotto@gmail.com

2 Prof. do Dept ${ }^{\mathrm{o}}$ de Fitotecnia Faculdade de Agronomia, Universidade Federal de Pelotas, UFPel, Pelotas, RS. E-mail: jfachi@

${ }^{3}$ Dr. Pesquisador Embrapa Uva e Vinho, Bento Gonçalves, RS. E-mail: alexandre.hoffmann@embrapa.br

${ }^{4}$ Dr $^{\text {as }}$ Bolsistas de Pós-doutorado da Faculdade de Agronomia, Dept ${ }^{\mathrm{o}}$ de Fitotecnia, UFPel, Pelotas, RS. E-mail: nicacia@gmail. com; sgalarça@superig.com.br

${ }^{5}$ Bolsistas de graduação Faculdade de Agronomia, Dept ${ }^{\circ}$ de Fitotecnia, UFPel, Pelotas, RS. E-mail: marcosprezotto@hotmail. com; luciane.haas@yahoo.com.br
} ufpel.edu.br

* Autor para correspondência 
or anticipate the beginning and the full bloom in up to eleven days. The estimated production and productivity per hectare of the 'Maciel' trees are greater when grafted on 'Flordaguard', and smaller when grafted on 'Umezeiro'.

Key words: Prunus persica (L.) Batsch, vegetative and productive behavior, soluble solids, incompatibility, peach

\section{Introdução}

Com área plantada de 20.194 hectares, a produção brasileira de pêssegos é crescente, alcançando 220.739 toneladas no ano de 2010, com produtividade média nacional de $10,93 \mathrm{t}$ ha $^{-1}$. Esta produção concentra-se na Região Sul, apresentando-se o Rio Grande do Sul como maior estado produtor, onde foram colhidas $132.874 \mathrm{t} \mathrm{em}$ área de 14.839 ha. Observa-se, no entanto, que a média de produtividade ainda está aquém do seu potencial, sendo de 8,95 $\mathrm{t} \mathrm{ha}^{-1}$ no Rio Grande do Sul, 12,37 t ha- em Santa Catarina, 10,23 t ha-1 no Paraná e 21,04 t ha'-1 em São Paulo (IBGE, 2012).

A menor produtividade gaúcha $\left(8,95 \mathrm{t} \mathrm{ha}^{-1}\right) \mathrm{em}$ relação aos demais estados produtores é atribuída, em parte, às mudas de baixa qualidade utilizadas pelos persicultores. Segundo Cardoso et al. (2011), devem ser utilizadas mudas de qualidade na implantação do pomar a fim de aumentar a produtividade do pessegueiro. A utilização de porta-enxertos possibilita o cultivo de inúmeras cultivares e espécies nos mais diversos climas e regiões, pois a muda enxertada carrega todas as características desejáveis, o que não acontece com mudas provenientes de sementes (PICOLOTTO et al., 2009).

Atualmente, as mudas produzidas no Rio Grande do Sul apresentam características distintas quanto ao método de obtenção dos porta-enxertos. Alguns poucos viveiristas do estado produzem mudas de qualidade adequada, fiscalizadas e que utilizam sementes do porta-enxerto Capdeboscq (o mais utilizado no estado), proveniente de plantas matrizeiras conhecidas. Por outro lado, a maior parte dos viveiristas não segue normas de fiscalização ou certificação, utilizando sementes coletadas nas indústrias conserveiras de Pelotas-RS, obtendo porta-enxertos de origem genética desconhecida e duvidosa. Estes, além de serem indevidamente denominados 'Capdeboscq', originarão mudas de baixa qualidade fitossanitária, desuniformes nos pomares e com características fenológicas desconhecidas.

Os porta-enxertos podem influenciar no desenvolvimento da cultivar, alterando a área de seção do tronco, altura, formato e crescimento da planta, ângulo de abertura dos ramos, nutrição da planta, potencial hídrico do xilema, fenologia, qualidade dos frutos, precocidade produtiva, produção, resistência a doenças e sobrevivência da planta (MAYER; PEREIRA, 2006; RATO et al., 2008; REMORINI et al., 2008; NAVA; MARODIN; SANTOS, 2009).

A incompatibilidade entre porta-enxerto e a cultivar copa é um fato bastante complexo e discutido e assume papel importante na fruticultura, pois há crescente demanda por novos portaenxertos e cultivares, devido à exigência comercial e produtiva.

Embora a utilização de porta-enxertos seja prática tradicional, a influência sobre o crescimento vegetativo, floração, produção e qualidade de frutos das cultivares não é totalmente conhecida. A avaliação precisa das respostas agronômicas e produtivas dos porta-enxertos e a identificação da melhor combinação da cultivar copa com o portaenxerto é importante para se obter produções de qualidade (RATO et al., 2008).

Sendo assim, o trabalho objetivou avaliar o vigor, a época de floração, a produção e a qualidade de pêssegos das cultivares Maciel e Chimarrita sobre diferentes porta-enxertos. 


\section{Material e Métodos}

O experimento foi realizado no pomar localizado na Embrapa Uva e Vinho, no município de Bento Gonçalves, RS (latitude $29^{\circ} 09^{\prime} 44^{\prime}$ S, longitude $51^{\circ} 31^{\prime} 50^{\prime}$ W e altitude $640 \mathrm{~m}$ ), numa área de 0,2 ha. O clima da região de acordo com a metodologia de Köppen, apresenta uma classificação $\mathrm{Cfb}$ que corresponde a um clima temperado quente $(\mathrm{C})$, com ausência de estação seca (f) e temperatura média do mês mais quente inferior a $22^{\circ} \mathrm{C}$ (b). Os valores anuais da temperatura média do ar e da precipitação pluvial são, respectivamente, $17,2^{\circ} \mathrm{C}$ e $1736 \mathrm{~mm}$ (CONCEIÇÃO; MANDELLI; ZAT, 2006). O solo no local do experimento, segundo Valladares e Luz (2005) é um Complexo de Nitossolo Bruno Alumínico argissólico + Neossolo Litólico Distrófico típico, ambos A moderado e proeminente, fase relevo suave ondulado.

Utilizaram-se pessegueiros das cultivares Maciel e Chimarrita enxertadas sobre as cultivares de portaenxertos de pessegueiros Aldrighi, Capdeboscq, Flordaguard, Nemaguard e Okinawa e sobre Umezeiro ou damasqueiro-japonês (Prunus mume) no espaçamento de 5,0 x 1,5 metros e conduzidas na forma de "V". O trabalho foi desenvolvido no período de agosto de 2008 a dezembro de 2009, perfazendo duas safras. As variáveis avaliadas de vigor foram: diâmetro do tronco $(\mathrm{cm})$; volume da copa $\left(\mathrm{m}^{3}\right)$; massa fresca do material vegetal retirado na poda de inverno (2008) e na poda verde (2008 e 2009) (g). O coeficiente de compatibilidade a campo (CCC) foi calculado por meio da fórmula modificada de Perraudine (1962), sendo Coef. Afinidade $=[(C / A)+(C+A) / 2 B]+10$, onde "A" diâmetro do tronco acima do ponto de enxertia, "B" diâmetro do tronco no ponto de enxertia e "C" diâmetro do tronco abaixo do ponto de enxertia, sendo que os parâmetros "A" e "C" foram medidos $5 \mathrm{~cm}$ acima e $5 \mathrm{~cm}$ abaixo do ponto de enxertia, respectivamente, em função do pequeno porte do tronco das plantas avaliadas.
Para época de floração das cultivares copa, as flores abertas foram contadas em cada data de avaliação, considerado o início da floração (IF) quando $10 \%$ das flores estavam abertas, plena floração (PF) com 50\% das flores abertas e final da floração (FF) na queda das pétalas das flores. Os resultados foram expressos em percentagem de flores abertas.

Para determinar a produção, avaliaram-se as seguintes variáveis: produção acumulada estimada por planta $\left(\mathrm{Kg} \mathrm{pl}^{-1}\right)$ e produtividade acumulada estimada por hectare $\left(\mathrm{t} \mathrm{ha}^{-1}\right)$.

Os frutos foram avaliados no Laboratório da Fruticultura - Departamento de Fitotecnia (UFPel), onde se realizaram as seguintes avaliações físicoquímicas: sólidos solúveis ( ${ }^{\circ}$ Brix); acidez titulável (AT) (\% de acidez); pH; relação SS/AT e firmeza de polpa (em libras-Lbs).

$\mathrm{O}$ delineamento experimental utilizado foi o de blocos ao acaso, unifatorial, constituído de 12 tratamentos (6 porta-enxertos e 2 cultivares copa) com 3 repetições, totalizando 36 parcelas. Utilizaram-se cinco plantas por repetição, sendo duas plantas de bordadura totalizando 15 plantas por tratamento. Para as avaliações físico-químicas dos pêssegos, foram utilizados 20 frutos por repetição. Os dados obtidos foram submetidos à análise da variância, através do Teste $\mathrm{F}$, e as médias comparadas pelo teste Tukey, onde $\mathrm{p}=0,05$. As análises foram realizadas com auxílio do Programa estatístico WinStat.

\section{Resultados e Discussão}

Os porta-enxertos utilizados influenciaram de forma significativa o diâmetro do tronco para as duas cultivares avaliadas e o volume de copa somente para 'Maciel' em 2009 (Tabela 1). Para a cv. Maciel, 'Nemaguard' e 'Okinawa' resultaram diâmetro do tronco superior, diferindo significativamente de 'Aldrighi' e 'Umezeiro' (2008) (Tabela 1). Em 2009, novamente 'Okinawa' aumentou o diâmetro de 
forma significativa, diferindo apenas de 'Umezeiro' (Tabela 1). Para cv. Chimarrita, 'Nemaguard' (2008) e 'Flordaguard' (2009) aumentaram enquanto 'Umezeiro' induziu o menor diâmetro do tronco (2008 e 2009) (Tabela 1). O volume de copa de 'Maciel' foi maior em 'Nemaguard' diferindo apenas de ‘Umezeiro' em 2009 (Tabela 1).

Analisando a constante de compatibilidade a campo (CCC) da cv. Maciel, que é a medida da afinidade de enxertia entre o porta-enxerto e a cultivar copa e, que segundo Gokbayrak, Soylemezoglu e Akkurt (2007), quanto mais próximo de 12, maior é a afinidade,foi mais próxima em 'Capdeboscq' $(11,944)$, já, para ‘Umezeiro', os valores foram mais distantes de 12(11,714)(Figura 1). Para 'Chimarrita', a CCC foi mais próxima de 12 para 'Capdeboscq' $(11,945)$ e 'Flordaguard' $(11,945)$ e mais distante para 'Umezeiro' $12(11,657)$ (Figura 1). Associado aos resultados da afinidade de enxertia, observou-se sintoma visual de desenvolvimento desproporcional do tronco nas combinações de 'Umezeiro' com 'Chimarrita' e 'Maciel', ocorrendo um pronunciado intumescimento no ponto de enxertia, em relação às porções superior e inferior do tronco do portaenxerto e da cultivar copa, caracterizado como um sintoma típico de incompatibilidade de enxertia. Além da observação da hipertrofia do ponto de enxertia de 'Umezeiro', enxertado sob 'Maciel' e 'Chimarrita', associam-se outros sintomas como o decréscimo na altura do diâmetro do tronco e do volume de copa, além da morte de duas plantas de 'Maciel' e duas de 'Chimarrita'.

Neste trabalho o vigor, expresso pelo diâmetro do tronco, variável que segundo Tomaz et al. (2010) tem relação direta com o volume de copa e de acordo com Rossi (2004) pode ser usada para estimar o potencial produtivo das plantas, foi maior nos portaenxertos Okinawa (2008 e 2009) e Nemaguard (2008) para a cv. Maciel e, Nemaguard (2008) e Flordaguard (2009) para a cv. Chimarrita (Tabela 1). Esses resultados revelam provável afinidade destes porta-enxertos às cultivares copa avaliadas e boa adaptação às condições edáficas e climáticas do município.Cita-se a tolerância aos solos ácidos, condição exigida por Nemaguard, e a satisfação da exigência em frio necessária pelo porta-enxerto Flordaguard (300 horas de frio abaixo de $7,2^{\circ} \mathrm{C}$ ). Os resultados observados para 'Okinawa', corroboram com o descrito por Finardi (1998), ao descrevê-lo como um dos porta-enxertos vigorosos.

As variáveis vegetativas analisadas também demonstraram menor vigor das duas cultivares sobre o porta-enxerto Umezeiro, sendo atribuído à menor afinidade entre as cultivares copa e o porta-enxerto e/ou a incompatibilidade. É importante destacar também o efeito ananizante do 'Umezeiro' que tem um funcionamento fisiologicamente diferenciado de indução do vigor, quando comparado aos portaenxertos vigorosos. Os de menor vigor possuem vasos do xilema condutores de seiva menores e menor é a condutância hidráulica, sendo que a capacidade das plantas para competir na captação de recursos do solo está relacionada à arquitetura da raiz (TOMBESI; ALMEHDI; DEJONG, 2011) limitando o crescimento da cultivar-copa devido à redução na produção de hormônios (auxinas e giberelinas) e/ou por dificultarem o transporte basípeto das auxinas nos seus tecidos (CANTÍN et al., 2010) e distribuírem prioritariamente a matéria seca pelas raízes e folhas, enquanto as árvores enxertadas em porta-enxertos mais vigorosos privilegiam também o crescimento do caule (BASILE et al., 2003). 
Tabela 1. Vigor e produção das cvs. Maciel e Chimarrita, enxertadas sobre diferentes porta-enxertos, em Bento Gonçalves, RS. FAEM/UFPel, Pelotas, RS. 2012.

\begin{tabular}{|c|c|c|c|c|c|c|c|c|}
\hline $\begin{array}{c}\text { Cultivar } \\
\text { Copa }\end{array}$ & Porta-enxerto & $\begin{array}{l}\text { V.C. }{ }^{1} \\
\left(\mathrm{~m}^{3}\right)\end{array}$ & P. Poda (g) & D.T. (cm) & $\begin{array}{c}\text { P. Plta } \\
\text { (Kg.pl) }\end{array}$ & P. ha $\left(t \cdot h \mathbf{a}^{-1}\right)$ & $\begin{array}{c}\text { P. Ac. (Kg. } \\
\text { pl) }\end{array}$ & $\begin{array}{c}\text { P. ha } \\
\text { Ac.(ton.ha) }\end{array}$ \\
\hline \multicolumn{9}{|c|}{ Ano de 2008} \\
\hline \multirow{6}{*}{ Maciel } & Aldrighi & $0,59^{\text {n.s. }}$ & $3.535,00^{\text {n.s }}$ & $4,01 \mathrm{~b}$ & $2,58 \mathrm{ab}$ & $3,44 \mathrm{ab}$ & & \\
\hline & Capdeboscq & 0,82 & $2.937,78$ & $5,42 a b$ & $4,36 \mathrm{a}$ & $5,81 \mathrm{a}$ & & \\
\hline & Flordaguard & 0,81 & $4.735,55$ & $5,20 \mathrm{ab}$ & $2,59 \mathrm{ab}$ & $3,45 \mathrm{ab}$ & & \\
\hline & Nemaguard & 0,80 & $6.061,00$ & $5,95 \mathrm{a}$ & $1,76 \mathrm{~b}$ & $2,34 \mathrm{~b}$ & & \\
\hline & Okinawa & 0,74 & $2.937,67$ & $6,02 \mathrm{a}$ & $2,57 \mathrm{ab}$ & $3,42 \mathrm{ab}$ & & \\
\hline & Umezeiro & 0,42 & $1.273,89$ & $4,01 \mathrm{~b}$ & $2,40 \mathrm{ab}$ & $3,20 \mathrm{ab}$ & & \\
\hline CV (\%) & & 31,73 & 63,38 & 12,71 & 27,93 & 27,89 & & \\
\hline \multirow{6}{*}{ Chimarrita } & Aldrighi & $0,56^{\text {n.s. }}$ & $1.710,00^{\text {n.s }}$ & $4,45 \mathrm{ab}$ & $3,71 \mathrm{ab}$ & $4,95 \mathrm{ab}$ & & \\
\hline & Capdeboscq & 0,61 & $2.396,23$ & $4,95 \mathrm{ab}$ & $2,07 \mathrm{~b}$ & $2,76 \mathrm{~b}$ & & \\
\hline & Flordaguard & 0,68 & $2.718,33$ & $5,24 \mathrm{ab}$ & $4,76 \mathrm{a}$ & $6,35 \mathrm{a}$ & & \\
\hline & Nemaguard & 0,67 & $3.250,00$ & $5,41 \mathrm{a}$ & $2,50 \mathrm{ab}$ & $3,34 \mathrm{ab}$ & & \\
\hline & Okinawa & 0,43 & $1.811,67$ & $4,93 \mathrm{ab}$ & $1,70 \mathrm{~b}$ & $2,27 \mathrm{~b}$ & & \\
\hline & Umezeiro & 0,21 & 474,67 & $3,64 \mathrm{~b}$ & $1,61 \mathrm{~b}$ & $2,14 \mathrm{~b}$ & & \\
\hline CV (\%) & & 32,77 & 67,46 & 12,21 & 31,18 & 31,17 & & \\
\hline \multicolumn{9}{|c|}{ Ano de 2009} \\
\hline \multirow{6}{*}{ Maciel } & Aldrighi & $2,38 \mathrm{ab}$ & 443,33 n.s. & $5,59 \mathrm{ab}$ & $3,60 \mathrm{ab}$ & $4,80 \mathrm{ab}$ & $6,13 a b c$ & $8,16 \mathrm{abc}$ \\
\hline & Capdeboscq & $2,60 \mathrm{ab}$ & 740,00 & $6,68 \mathrm{ab}$ & $1,94 \mathrm{ab}$ & $2,59 \mathrm{ab}$ & $6,30 \mathrm{ab}$ & $8,40 \mathrm{ab}$ \\
\hline & Flordaguard & $2,25 \mathrm{ab}$ & 416,67 & $6,63 \mathrm{ab}$ & $5,38 \mathrm{a}$ & $7,17 \mathrm{a}$ & $7,73 \mathrm{a}$ & $10,31 \mathrm{a}$ \\
\hline & Nemaguard & $3,74 \mathrm{a}$ & 850,00 & $6,54 \mathrm{ab}$ & $1,31 \mathrm{ab}$ & $1,75 \mathrm{ab}$ & $3,02 \mathrm{bc}$ & $4,02 \mathrm{bc}$ \\
\hline & Okinawa & $2,69 \mathrm{ab}$ & 386,67 & $7,31 \mathrm{a}$ & $0,30 \mathrm{~b}$ & $0,40 \mathrm{~b}$ & $2,88 \mathrm{bc}$ & 3,85 bc \\
\hline & Umezeiro & $1,04 \mathrm{~b}$ & 246,67 & $4,83 \mathrm{~b}$ & $0,23 \mathrm{~b}$ & $0,30 \mathrm{~b}$ & $2,67 \mathrm{c}$ & $3,55 \mathrm{c}$ \\
\hline CV (\%) & & 35,16 & 92,72 & 13,78 & 77,30 & 77,29 & 26,73 & 26,72 \\
\hline \multirow{6}{*}{ Chimarrita } & Aldrighi & $1,60^{\mathrm{n} . \mathrm{s}}$ & $526,67^{\text {n.s. }}$ & $5,28 \mathrm{ab}$ & $2,60 \mathrm{ab}$ & $3,47 \mathrm{ab}$ & $6,84 \mathrm{ab}$ & $9,01 \mathrm{ab}$ \\
\hline & Capdeboscq & 1,43 & 296,67 & $5,84 \mathrm{ab}$ & $5,66 \mathrm{a}$ & $7,54 \mathrm{a}$ & $7,73 \mathrm{ab}$ & $10,12 \mathrm{ab}$ \\
\hline & Flordaguard & 1,77 & 473,33 & $6,77 \mathrm{a}$ & $3,56 \mathrm{ab}$ & $4,74 \mathrm{ab}$ & $9,15 \mathrm{a}$ & $12,06 \mathrm{a}$ \\
\hline & Nemaguard & 2,14 & 680,00 & $5,29 \mathrm{ab}$ & $2,50 \mathrm{ab}$ & $3,34 \mathrm{ab}$ & $5,37 \mathrm{ab}$ & $7,07 \mathrm{ab}$ \\
\hline & Okinawa & 1,23 & 236,67 & $5,81 \mathrm{ab}$ & $3,67 \mathrm{ab}$ & $4,90 \mathrm{ab}$ & $5,96 \mathrm{ab}$ & $7,81 \mathrm{ab}$ \\
\hline & Umezeiro & 0,62 & 343,33 & $4,33 \mathrm{~b}$ & $1,07 \mathrm{~b}$ & $1,42 \mathrm{~b}$ & $2,87 \mathrm{~b}$ & $3,78 \mathrm{~b}$ \\
\hline CV (\%) & & 49,76 & 91,49 & 11,74 & 42,97 & 42,97 & 31,50 & 31,09 \\
\hline
\end{tabular}

* Médias seguidas pela mesma letra minúscula na coluna não diferem entre si pelo teste de Tukey ( $\leq \leq 0,05)$. "n.s" = não significativo. ${ }^{1}$ V.C. $=$ Volume de Copa ; P. Poda $=$ Peso de Poda ; D. T. $=$ Diâmetro do Tronco ; P. Plta = Produção por Planta ; P. ha = Produtividade por Hectare ; P. Ac. = Produção Acumulada ; P. ha Ac. = Produtividade por Hectare Acumulada Peso poda Bento 2009 refere-se ao peso de poda de verão.

Fonte: Elaboração dos autores. 
Figura 1. Constante de compatibilidade a campo (CCC) das cvs. Maciel e Chimarrita enxertadas sobre diferentes porta-enxertos, em Bento Gonçalves, RS. FAEM/UFPel, Pelotas, RS. 2012.

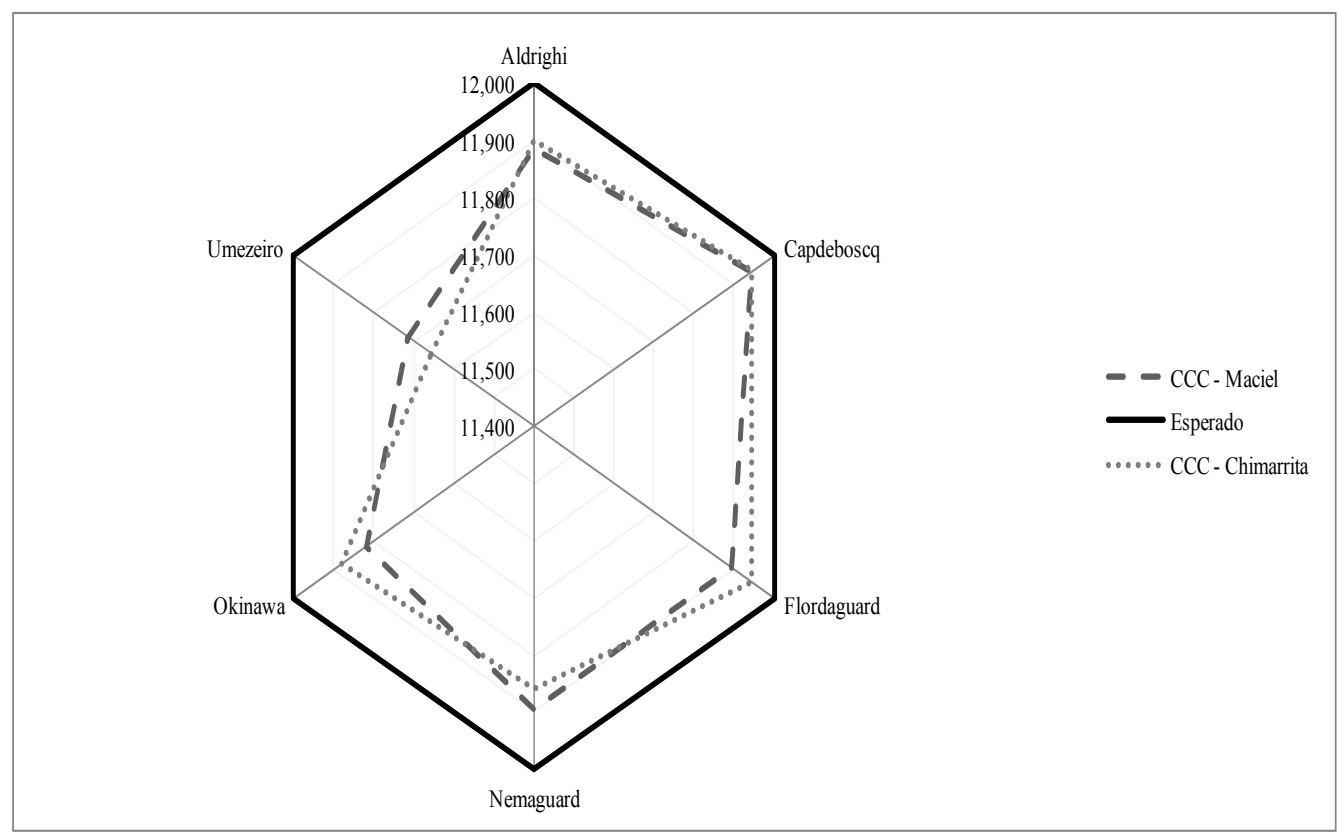

Fonte: Elaboração dos autores.

A época de floração de 'Maciel' e 'Chimarrita' foi influenciada pelos diferentes porta-enxertos, iniciando em final de junho e terminando em início de agosto de 2008. Sobre a cultivar Maciel, 'Aldrighi' antecipou o IF (28/06) e 'Capdeboscq' e 'Okinawa' retardaram o IF (02/07) diferindo em quatro dias (Tabela 2). A PF de 'Maciel' foi antecipada, quando enxertada sobre 'Flordaguard', 'Aldrighi' e 'Nemaguard' (06/07) e retardada em 'Capdeboscq' (09/07), diferindo três dias (Tabela 2). Sobre 'Maciel' merece destaque o retardamento, tanto no IF quanto na $\mathrm{PF}$, induzido principalmente por 'Capdeboscq', o qual pode ser útil, sobretudo quando há ocorrência de geadas tardias. Para 'Chimarrita', o IF foi antecipado por 'Capdeboscq' (30/06) e houve retardamento por 'Nemaguard' e 'Umezeiro' (11/07), diferindo em onze dias a indução do IF (Tabela 2). A PF de 'Chimarrita', foi induzida primeiramente por 'Flordaguard' e 'Aldrighi' (19/07) e ultimamente por 'Umezeiro' (24/07), diferindo cinco dias (Tabela 2).

A influência observada quanto ao retardo e a antecipação da floração sobre as duas cultivares analisadas neste trabalho corroboram com Rossi et al. (2004), que verificaram, para o pessegueiro 'Granada', enxertada em diferentes porta-enxertos, nas condições de Pelotas, RS, diferenças de dez e cinco dias na indução da plena floração, durante os dois anos de avaliação.

A produção das duas cultivares copa foi influenciada pelos diferentes porta-enxertos. Tanto para 'Maciel' quanto para 'Chimarrita' os portaenxertos Flordaguard e Umezeiro induziram, respectivamente, a maior e a menor produção e produtividade acumulada (Tabela 1). 
Tabela 2. Início, plena e final da floração das cvs. Maciel e Chimarrita, enxertadas sobre diferentes porta-enxertos, em Bento Gonçalves, RS. FAEM/UFPel, Pelotas, RS. 2012.

\begin{tabular}{clccc}
\hline Cultivar copa & Porta-enxerto & Início floração & Plena floração & Final da floração \\
\hline \multirow{6}{*}{ Maciel } & Aldrighi & $28 / 6$ & $6 / 7$ & $17 / 7$ \\
& Capdeboscq & $2 / 7$ & $9 / 7$ & $18 / 7$ \\
& Flordaguard & $30 / 6$ & $6 / 7$ & $14 / 7$ \\
& Nemaguard & $29 / 6$ & $6 / 7$ & $15 / 7$ \\
& Okinawa & $2 / 7$ & $8 / 7$ & $20 / 7$ \\
& Umezeiro & $30 / 6$ & $8 / 7$ & $16 / 7$ \\
\hline \multirow{6}{*}{ Chimarrita } & Aldrighi & $1 / 7$ & $20 / 7$ & $28 / 7$ \\
& Capdeboscq & $6 / 7$ & $20 / 7$ & $29 / 7$ \\
& Flordaguard & $11 / 7$ & $19 / 7$ & $29 / 7$ \\
& Nemaguard & $5 / 7$ & $20 / 7$ & $29 / 7$ \\
& Okinawa & $11 / 7$ & $21 / 7$ & $3 / 8$ \\
& Umezeiro & & $24 / 7$ & $1 / 8$ \\
\hline
\end{tabular}

Fonte: Elaboração dos autores.

Os valores de produção por planta obtidos não podem ser considerados expressivos do potencial de cada porta-enxerto, haja visto que as plantas ainda não tinham atingido plena produção, pois estavam em seu segundo (2008) e terceiro (2009) ano de produção, embora o efeito do porta-enxerto já podia ser observado. Stern e Doron (2009), relatam ter encontrado efeito dos porta-enxertos na cultivar de pêra 'Coscia' somente a partir do quarto ano de produção, se expandindo ano a ano, verificando no nono ano de avaliação diferenças consideráveis e significantes.

Os resultados positivos induzidos sobre a produção observados para 'Flordaguard' podem ser atribuídos a sua afinidade com as cultivares copa Maciel e Chimarrita e a adaptações às condições climáticas de Bento Gonçalves, RS. Enfatiza-se que o local teve acúmulo de 300 horas de frio abaixo de $7,2^{\circ} \mathrm{C}$ nas duas safras avaliadas, necessárias para superar a dormência e induzir o florescimento, influenciando diretamente na produção.

Esperava-se, ainda, que 'Maciel' e 'Chimarrita' enxertadas sobre 'Umezeiro', tivessem maior produção por planta, em função das características ananizantes e de precocidade deste porta-enxerto, no entanto, o mesmo induziu os menores valores de produção, atribuindo-se à falta de afinidade e a problemas de incompatibilidade que impedem ou limitam a absorção e translocação de água, sais minerais e carboidratos disponíveis, destacando-se o último, pela formação das gemas floríferas.

As diferenças na época de floração e produção provavelmente ocorrem devido à indução de vigor do porta-enxerto, pois, conforme observaram RizkAlla; Sabry e Abd El-Wahab (2011) ao avaliarem diferentes porta-enxertos de videira sobre 'Red Globe', os mais vigorosos induziram maior crescimento da área foliar da copa, reduziram a passagem de sol às gemas e prejudicaram a diferenciação das mesmas alterando a fertilidade das gemas reprodutivas e, consequentemente a produção. Daza et al. (2008) também destacam a relação entre os porta-enxertos e condições climáticas ocorridas durante a estação de diferenciação das gemas reprodutivas do pessegueiro como fortes e complexas, com variações significativas ano-a-ano.

As características físico-químicas dos frutos de 'Maciel' foram influenciadas pelos porta-enxertos em 2008 e somente o $\mathrm{pH}$ e a firmeza de polpa em 2009 (Tabela 3). Frutos de 'Maciel' com valores de $\mathrm{pH}$ significativamente superior e inferior foram obtidos quando a cultivar foi enxertada sobre 'Flordaguard' e 'Okinawa', respectivamente em 2009 (Tabela 3). Pêssegos 'Maciel' mais firmes foram verificados quando enxertados sobre 'Okinawa' (Tabela 3). 
Tabela 3. Sólidos solúveis (SS), acidez titulável (AT), relação SS/AT, pH e firmeza da polpa de pêssegos das cvs. Maciel e Chimarrita, enxertadas sobre diferentes porta-enxertos, em Bento Gonçalves, RS. FAEM/UFPel, Pelotas, RS. 2012.

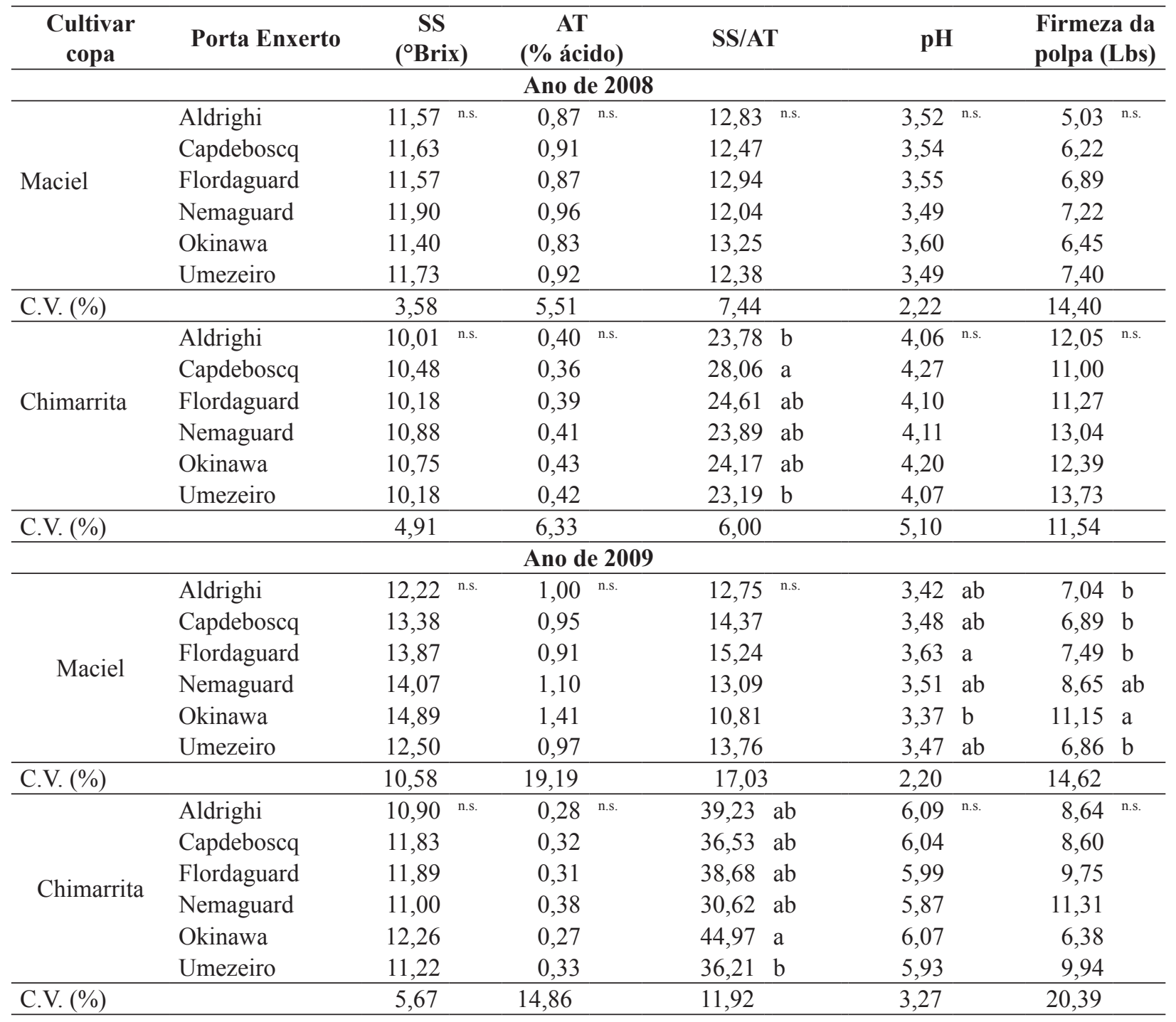

* Medias seguidas pela mesma letra minúscula na coluna não diferem entre si pelo teste de Tukey ( $\leq \leq 0,05)$. "ns" = não significativo. Fonte: Elaboração dos autores.

Frutos de 'Chimarrita' tiveram maior relação SS/ AT quando enxertados sobre 'Capdeboscq' (2008) e sobre 'Okinawa' (2009), e somente diferiram de 'Umezeiro', que induziu os menores valores, nos dois anos de avaliação (Tabela 3). A baixa relação SS/AT verificada em 'Umezeiro' demonstra menor sabor e pode indicar mais baixa qualidade dos pêssegos, pois, segundo Meredith, Robertson e Hovart (1989) esse parâmetro é considerado um bom indicador para frutas de alta qualidade. Os dados deste trabalho corroboram em parte com Picolotto et al. (2009), os quais observaram maior relação SS/AT da cv. Chimarrita, quando enxertada sobre 'Capdeboscq' e 'Tsukuba 1' e discordam de Mathias et al. (2008), os quais verificaram influência da relação SS/AT ao analisar pêssegos cv. 'Aurora-1', enxertados sobre o Clone 15 de 'Umezeiro'.

A firmeza de polpa dos pêssegos foi superior em frutos de 'Maciel', enxertados sobre 'Okinawa', podendo indicar adaptação deste porta-enxerto à 
cultivar copa enxertada e ao local de cultivo, através da maior absorção de água e nutrientes e passagem desses nutrientes sem obstrução pelo xilema sendo posteriormente enviados aos frutos. Isso foi observado por Cantín et al. (2010) ao verificar firmeza de polpa significativamente superior quando as cultivares de cereja 'Van' e 'SHG' foram enxertadas sobre Adara, um porta-enxerto vigoroso. Rato et al. (2008) relataram correlações positivas entre a firmeza da polpa dos frutos e o maior teor de cálcio, atribuindo a este nutriente a maior firmeza de polpa dos frutos.

\section{Conclusões}

1 - As cvs. Maciel e Chimarrita, quando enxertadas sobre 'Umezeiro', apresentam menor vigor e sintomas de incompatibilidade;

2- A floração dos pessegueiros das cvs. Maciel e Chimarrita é influenciada pelos porta-enxertos, podendo retardar ou antecipar o início e a plena floração em até onze dias;

3- A produção e produtividade acumulada estimada por hectare da cv. Maciel é maior quando enxertada sobre 'Flordaguard' e menor sobre 'Umezeiro'.

\section{Agradecimentos}

Os autores agradecem ao CNPQ e à FAEM/ UFPel pelo apoio.

\section{Referências}

BASILE, B.; MARSAL, J.; SOLARI, I.; TYREE, M. T.; BRYLA, D. R.; DEJONG, T. M. Hydraulic conductance of peach trees grafted on rootstocks with differing sizecontrolling potentials. Journal of Horticultural Science \& Biotechnology, Davis, v. 78, n. 6, p.768-774, 2003.

CANTÍN, C. M.; PINOCHET, J.; GOGORCENA, Y.; MORENO, M. A. Growth, yield and fruit quality of 'Van' and 'Stark Hardy Giant' sweet cherry'cultivars as influenced by grafting on different rootstocks. Scientia Horticulturae, Amsterdam, v. 123, n. 3, p. 329-335, 2010.
CARDOSO, C.; YAMAMOTO, L. Y.; PRETI, E. A.; ASSIS, A. M. de; NEVES, C. S. J.; ROBERTO, S. R. AIB e substratos no enraizamento de estacas de pessegueiro 'Okinawa' coletadas no outono. Semina: Ciências Agrárias, Londrina, v. 32, n. 4, p. 1307-1314, 2011.

CONCEIÇÃO, M. A. F.; MANDELLI, F.; ZAT, D. A. Variações climáticas na Região da Serra Gaúcha. Bento Gonçalves: Embrapa CNPUV, 2006. 4 p. (Embrapa CNPUV, Comunicado técnico, 70).

DAZA, A.; GARCÍA-GALAVÍS, P. A.; GRANDE, M. J.; SANTAMARÍA, C. Fruit quality parameters of 'Pioneer' Japanese plums produced on eight different rootstocks. Scientia Horticulturae, Amsterdam, v. 118, n. 3, p. 206211, 2008.

FINARDI, N. L. Método de propagação e descrição de porta-enxertos. In: MEDEIROS, C. A. B.; RASEIRA, M. C. B. (Ed.). A cultura do pessegueiro. Pelotas: EMBRAPA/CPACT, 1998. p. 100-128.

GOKBAYRAK, Z. G.; SOYLEMEZOGLU, M.; AKKURT, H. Ç. Determination of grafting compatibility of grapevine with electrophoretic methods. Scientia Horticulturae, Amsterdam, v. 113, n. 4, p. 343-352, 2007.

INSTITUTO BRASILEIRO DE GEOGRAFIA E ESTATÍSTICA - IBGE. Produção agrícola municipal. 2012 Disponível em: <http://www.sidra.ibge.gov.br/bda/ tabela/listabl.asp? $\mathrm{z}=\mathrm{t} \& \mathrm{o}=11 \& \mathrm{i}=\mathrm{P} \& \mathrm{c}=1613>$. Acesso em: 10 fev. 2012.

MATHIAS, C.; MAYER, N. A.; MATTIUZ, B.; PEREIRA, F. M. Efeito de porta-enxertos e espaçamentos entre plantas na qualidade de pêssegos 'AURORA-1'. Revista Brasileira Fruticultura, Jaboticabal, v. 30, n. 1, p. 165-170, 2008.

MAYER, N. A.; PEREIRA, F. M. Vigor de clones de umezeiro e pessegueiro 'Okinawa' propagados por estacas herbáceas. Pesquisa Agropecuária Brasileira, Brasília, v. 41, n. 5, p. 883-887, 2006.

MEREDITH, F. I.; ROBERTSON, J. A.; HOVART, R. J. Changes in physical and chemical parameters associatedwith quality de postharvest ripening of harvests peaches. Journal Agricultural and Food Chemistry, Washington, v. 37, n. 5, p. 1210-1214, 1989.

NAVA, G. A.; MARODIN, G. A. B.; SANTOS, R. P. dos. Reprodução do pessegueiro: efeito genético, ambiental e de manejo das plantas. Revista Brasileira Fruticultura, Jaboticabal, v. 31, n. 4, p. 1218-1233, 2009.

PERRAUDINE. La Pomologie Françoise. Lyon: L. Chasset, 1962. 
PICOLOTTO, L.; MANICA-BERTO, R.; PAZIN, D.; PASA, M. S.; SCHMITZ, J. D.; PREZOTTO, M. E.; BETEMPS, D.; BIANCHI, V. J.; FACHINELLO, J. C. Características vegetativas, fenológicas e produtivas do pessegueiro cultivar Chimarrita enxertado em diferentes porta-enxertos. Pesquisa Agropecuária Brasileira, Brasília, v. 44, n. 6, p. 583-589, 2009.

RATO, A. E.; AGUlheiro, A. C.; BARroso, J. M.; RIQUELME, F. Soil and rootstock influence on fruit quality of plums (Prunus domestica L.). Scientia Horticulturae, Amsterdam, v. 118, n. 3, p. 218-222, 2008.

REMORINI, D.; TAVARINI, S.; DEGL'INNOCENTI, E.; LORETI, F.; MASSAI, R.; GUIDI, L. Effect of rootstocks and harvesting time on the nutritional quality of peel and flesh of peach fruits. Food Chemistry, London, v. 110, n. 2, p. 361-367, 2008.

RIZK-ALLA, M. S.; SABRY, G. H.; ABD EL-WAHAB, M. A. Influence of some rootstocks on the performance of red globe grape cultivar. Journal of American Science, New York, v. 7, n. 4, p. 71-81, 2011.

ROSSI, A. Avaliação bioagronomica de pessegueiro Granada e Suncrest sobre diferentes porta-enxertos. 2004. Tese (Doutorado em Fruticultura de Clima Temperado) - Faculdade de Agronomia Eliseu Maciel. Universidade Federal de Pelotas, Pelotas.
ROSSI, A.; FACHINELLO, J. C.; RUFATO, L.; PARISOTO, E.; PICOLOTTO, L.; KRUGER, L. R. Comportamento do pessegueiro 'Granada' sobre diferentes porta-enxertos. Revista Brasileira de Fruticultura, Jaboticabal, v. 26, n. 3, p. 446-449, 2004.

STERN, R. A.; DORON, I. Performance of 'Coscia' pear (Pyrus communis) on nine rootstocks in the north of Israel. Scientia Horticulturae, Amsterdan, v. 3, n. 119, p. 252-256, 2009.

TOMAZ, Z. T.; LIMA, C. S. M.; GONÇALVES, M. A.; RUFATO, L.; RUFATO, A. R. Crescimento vegetativo, floração e frutificação efetiva do pessegueiro 'Jubileu' submetido a diferentes comprimentos de interenxertos. Pesquisa Agropecuária Brasileira, Brasília, v. 45, n. 9, p. 973-979, set. 2010.

TOMBESI, S.; ALMEHDI, A.; DEJONG, T. M. Phenotyping vigour control capacity of new peach rootstocks by xylem vessel analysis. Scientia Horticulturae, Amsterdam, v. 127, n. 3, p. 353-357, 2011.

VALLADARES, G. S.; LUZ, N. B. Levantamento pedológico do campo experimental da Embrapa uva e vinho em Bento Gonçalves, RS. Campinas: Embrapa Monitoramento por Satélite, 2005. 78 p. (Embrapa Embrapa Monitoramento por Satélite, Boletim de Pesquisa e Desenvolvimento, 4). 